Research Article

\title{
Insights into Unloading Relaxation Mechanism of Columnar Jointed Basalt at the Baihetan Left Dam Foundation
}

\author{
Jian-cong Zhang $\mathbb{D}^{1,2}$ Shu-feng Pei $\mathbb{D}^{3},{ }^{3}$ Xiao Xu, ${ }^{4}$ and Hao-ran Li $\mathbb{D}^{3}$ \\ ${ }^{1}$ State Key Laboratory of Geomechanics and Geotechnical Engineering, Institute of Rock and Soil Mechanics, \\ Chinese Academy of Sciences, Wuhan, Hubei 430071, China \\ ${ }^{2}$ University of Chinese Academy of Sciences, Beijing 100049, China \\ ${ }^{3}$ College of Geosciences and Engineering, North China University of Water Resources and Electric Power, Zhengzhou, \\ Henan 450046, China \\ ${ }^{4}$ National Field Observation and Research Station of Landslides in Three Gorges Reservoir Area of Yangtze River, \\ China Three Gorges University, Yichang 443002, China \\ Correspondence should be addressed to Shu-feng Pei; peishufeng@ncwu.edu.cn
}

Received 5 March 2021; Revised 18 March 2021; Accepted 12 April 2021; Published 26 April 2021

Academic Editor: Xianjie Hao

Copyright (c) 2021 Jian-cong Zhang et al. This is an open access article distributed under the Creative Commons Attribution License, which permits unrestricted use, distribution, and reproduction in any medium, provided the original work is properly cited.

Columnar jointed basalt (CJB), characterized by unique geometric and geological properties, poses a great challenge for geotechnical designs due to its unloading relaxation and damage during excavation. In this paper, the geometrical structure and field failures of the CJB exposed on Baihetan left dam foundation were briefly presented. A systematic field test was conducted to study the excavation damage zone of the CJB on the dam foundation using ultrasonic $\mathrm{P}$ wave measurements. The excavation damage zone of the CJB not only showed time-dependent damage in depth but also showed spatially inhomogeneous distribution in depth. Corresponding three-dimensional numerical analysis was also carried out to analyze the unloading relaxation mechanism of CJB. The unloading relaxation of CJB on dam foundation was mainly caused by the joint opening under tension stress during excavation. The difference of excavation damage zone of the CJB located in different test zones was also discussed in this article.

\section{Introduction}

Bedding, joints, and fissures widely exist in engineering rock mass after complex diagenetic and mineralization processes and supergene evolution, which exhibits extremely complicated mechanical behavior [1-3]. During the excavation of jointed rock masses, the joints often tend to be loose or open due to the relief of stress, which in turn can often lead to damage in the entire jointed rock mass. Unloading relaxation of jointed rock masses generally leads to shearing deformation and slipping failure of the whole joint, resulting in collapse or sliding of the jointed rock mass [4-6].

Columnar joints of some kind are characterized by the spontaneous joint network of interconnected tension fractures which split the solids in a set of parallel columns [7-9]. As a typical example of an embedded joint rock mass, the columnar jointed rock mass contains a large number of intercolumn joint surfaces and hidden joint surfaces, which are more prone to unloading relaxation $[10,11]$. The socalled excavation damage zone (EDZ) is often used to describe unloading relaxation of rock masses [12, 13]. The relaxation characteristics of jointed rock masses are mainly evaluated by the relaxation depth and degree of relaxation obtained by the in situ single-hole acoustic test [14]. The in situ testing technology provides a key tool to understand the real damage behavior of jointed rock masses, because no laboratory experiments can reproduce the actual geostress conditions and the complex engineering situation. Many scholars have used this method to study the relaxation depth of columnar jointed rock masses. Meaningful findings on rock mass damage have been reported, such as the size effect and time effect of unloading relaxation. Fan et al. [15, 16] studied the deformation and relaxation characteristics of columnar jointed basalt (CJB) under excavation and 
unloading by means of field investigation and in situ testing. Jiang et al. [17-19] conducted long-term continuous observations on the unloading relaxation characteristics of the CJB on the Baihetan left dam foundation and the columnar joint of the diversion tunnel, revealing its transversely isotropic mechanical properties and time effect of the excavation damage zone.

Prior investigations and tests have also shown that the CJB has a low deformation modulus and strength and thus results in collapse of the underground cavern and slope instability for the dam foundation. Xu et al. [20-23] established a geometric generalization model based on the basic characteristics of the columnar jointed rock mass and estimated the equivalent deformation parameters and equivalent strength parameters of the columnar joints at different scales through the discrete element 3DEC software. Shi et al. [24] studied the joint characteristics, mechanical properties, and deformation mechanism of CJB. Other scholars [25-29] discussed the joint characteristics of CJB and the influence of the stress field characteristics of surrounding rock after excavation of the cavern. These studies provide a basis for the study of the relaxation characteristics of CJB. However, the unloading relaxation mechanism of columnar jointed rock masses during excavation is insufficient. Thus, the unloading and relaxation mechanism of CJB in high slope dam foundation under complex geological conditions needs to be studied.

In the present work, we carried out a detailed long-term continuous observation of excavation damage zone of the CJB on Baihetan left dam foundation. The field test data were obtained from the ultrasonic wave detection of 30 boreholes in the CJB test zone at 650 660 m elevation. The evolution of the entire damaged depth after excavation and the spatial distribution of the depth of EDZ were studied. Then, the unloading relaxation mechanism of CJB damage mechanism was investigated by three-dimensional numerical analysis. The difference of damage depth of CJB located in different zones on the Baihetan dam foundation is discussed with numerical analysis and the aid of additional field observations.

\section{Background of the Baihetan Dam Foundation}

2.1. Project Introduction. The Baihetan Hydropower Station is located on the lower reaches of the Jinsha River, China, with its left bank on the side of Ningnan County in Sichuan Province and its right bank on the side of Qiaojia County in Yunan Province. Its concrete dam, designed as a doublecurvature arch format, is situated in an unsymmetrical $\mathrm{V}$-shaped valley. The left dam foundation is a wide and gentle platform above $850 \mathrm{~m}$ in altitude, and steep and gentle slopes are alternately below $850 \mathrm{~m}$; the right dam foundation is gentle slope terrain above $1170 \mathrm{~m}$ in altitude and steep slope below $1170 \mathrm{~m}$ [30, 31].

The rock lithology is primarily composed of amygdaloidal basalt, aphanitic basalt intercalated brecciated lava, and CJB. The stratigraphic is built from the Permian Emeishan Group $\left(\mathrm{P}_{2} \beta\right)$ basalt flow layers, which are originated from magmatic and volcanic eruptions. The basalt on the dam site belongs to the upper Permian system $\left(\mathrm{P}_{2} \beta_{4}^{2} \sim \mathrm{P}_{2} \beta_{3}^{3}\right)$, and the typical CJB exposed on the dam foundation ranges from 575 to $670 \mathrm{~m}$ in altitude on the left bank.

The pedestal is set at $834 \sim 750 \mathrm{~m}$ in altitude on the left dam foundation. The expanded foundation is set below $750 \mathrm{~m}$ in altitude. The dam foundation is excavated with a reserved protective layer at $660 \sim 628 \mathrm{~m}$ in altitude, which is divided into 7 steps with a slope height of $5 \mathrm{~m}$ per step and excavation slope ratio of about $1: 1.2$. The test zone of CJB is set at $660 \sim 650 \mathrm{~m}$ in altitude, with a $2 \mathrm{~m}$ reserved protection layer. The 2\# WML hole and 2\# PSL hole are set at $660 \mathrm{~m}$ in altitude. The excavation pattern of dam foundation in left bank is shown in Figure 1.

2.2. Geostress of the Dam Site. The determination of the geostress field in the dam site is based on the cracks in the hole wall obtained by hydraulic fracturing, combined with the development degree of rib spalling and the orientation of the audit, core disking, and other phenomena. The comprehensive analysis of geostress in the dam zone shows that the first principal stress direction in the left dam site is basically consistent with the tendency of the rock layer, with the direction of $\mathrm{NW} 40^{\circ}$, dip angle is $15^{\circ}$, and the magnitude is $8 \mathrm{MPa} \sim 11 \mathrm{MPa}$; the second principal stress direction is $\mathrm{NE} 12^{\circ}$, dip angle is $-48^{\circ}$, and the magnitude is $7 \mathrm{MPa} 99 \mathrm{MPa}$; and the third principal stress direction is $\mathrm{NE}^{\circ} 4^{\circ}$ dip angle is $-29^{\circ}$, and the magnitude is $6 \mathrm{MPa} \sim 8 \mathrm{MPa}$.

\subsection{Unloading Relaxation Failure of Columnar Jointed Basalt} on Left Dam Foundation. The CJB was widely exposed on the left dam foundation during excavation, located at below $670 \mathrm{~m}$ in altitude. The CJB is characterized by small columnar blocks with irregular polygons in cross-section, and the axis trends towards the valley with a dip angle of approximately $70^{\circ} \sim 85^{\circ}$. The intercolumnar joint surface is straight and rough at the decimeter scale, and the microfissures are developed in columns at the centimeter scale. The typical columnar joints revealed by excavation in the dam foundation are shown in Figure 2.

The field investigation showed that this exposed columnar jointed rock mass mainly exhibited two types of failure mode, such as joint opening and shearing dislocation. The shearing dislocation of columnar jointed rock mass may cause extra shearing deformation and even local collapse due to the reduced frictional resistance if no appropriate supporting measurements were applied, as shown in Figure 3(a). The opening of columnar jointed rock mass may cause the cracking of the intralayer dislocation zone LS3319 on the dam foundation, as shown in Figure 3(b).

The unloading relaxation damage of the exposed CJB has become a key constraint affecting the construction of dam foundation at the Baihetan Hydropower Station, including optimization of the excavation and control of the unloading rebound of the dam foundation. To ensure the stability of the dam foundation at the Baihetan Hydropower Station, it is 


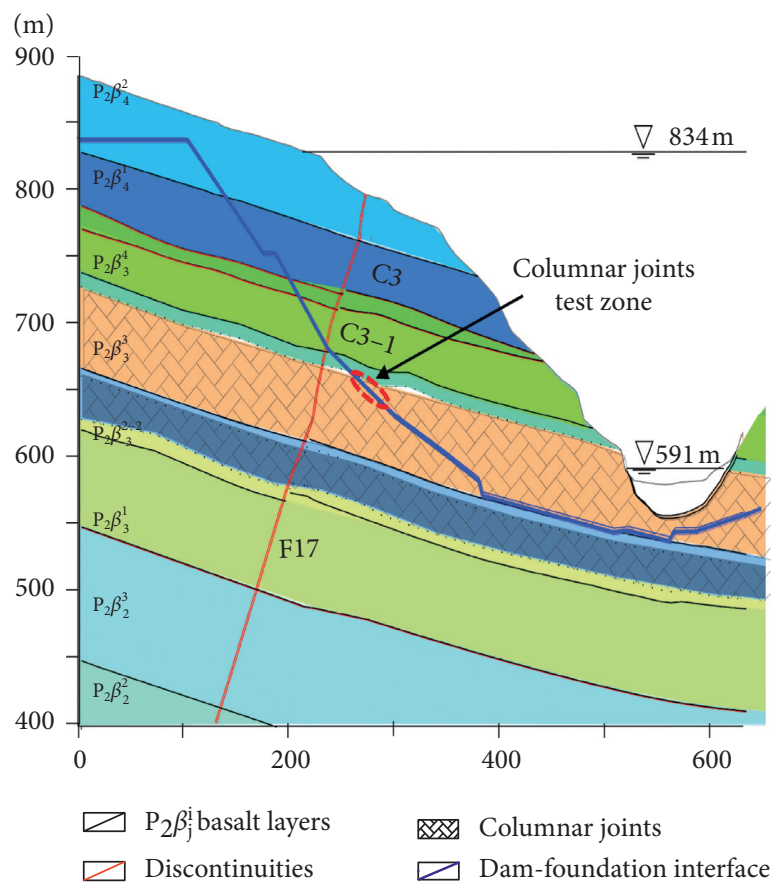

(a)

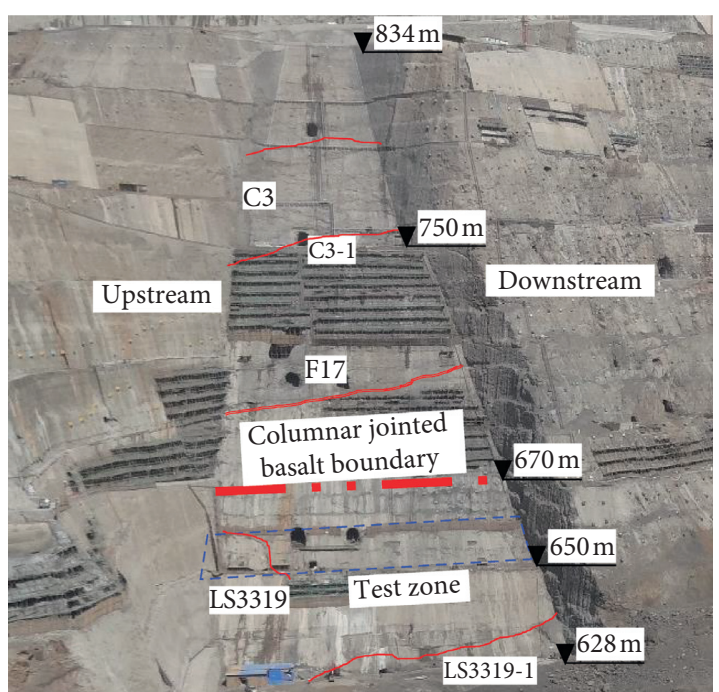

(b)

Figure 1: Excavation layout of the left dam foundation. (a) Geological profile of dam foundation; (b) excavated cross-section of dam foundation.
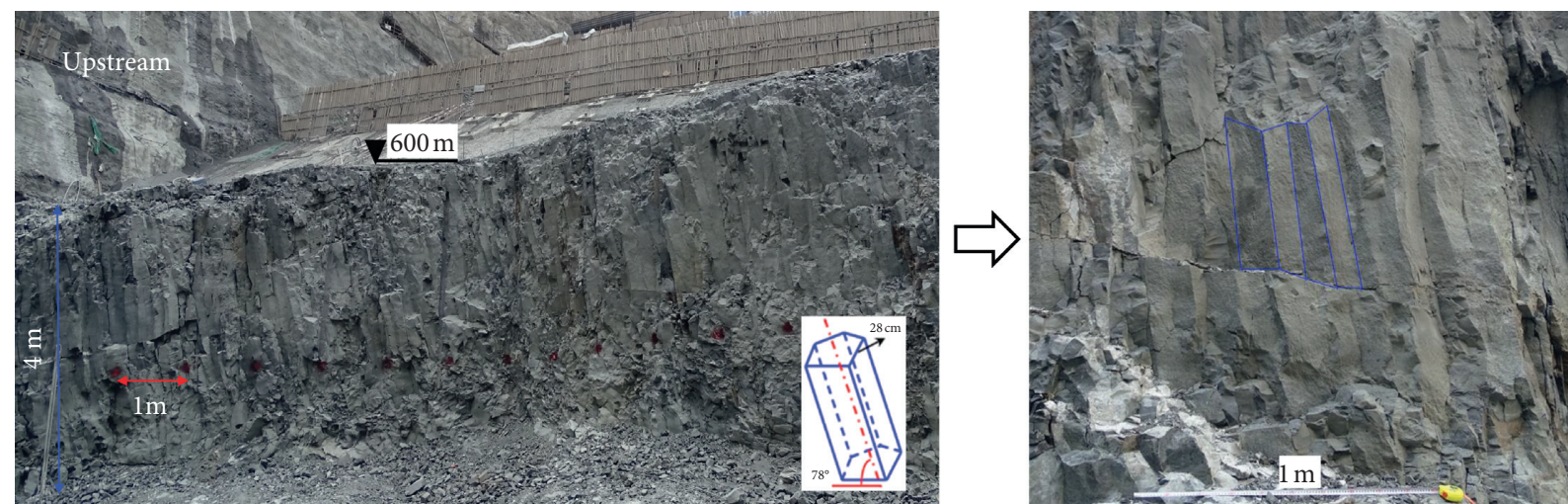

FIGURE 2: Typical CJB revealed at the left dam foundation.

necessary to conduct a systematic research on unloading relaxation mechanism of the CJB.

\section{In Situ Test of Unloading Relaxation of Columnar Jointed Basalt}

3.1. Layout of the Columnar Jointed Basalt Test Zone. In order to understand the unloading relaxation of the CJB on the left dam foundation during the excavation stage, a rectangular experimental zone of $90 \mathrm{~m}$ in length and $14 \mathrm{~m}$ in height on the dam base is selected to conduct the field testing, and the excavation slope ratio is about $1: 1.2$. The test zone is distributed in $\mathrm{A} 1$ region, $\mathrm{B} 1$ region, and $\mathrm{B} 2$ region at elevation of $660 \sim 655 \mathrm{~m}$, and $\mathrm{A} 2$ region, $\mathrm{C} 1$ region, and $\mathrm{C} 2$ region are distributed at elevation of $655 \sim 650 \mathrm{~m}$. A1 region and A2 region are located on the upstream side of the dam foundation, $\mathrm{B} 1$ region and $\mathrm{C} 1$ region are located on the middle of the dam foundation, and $\mathrm{B} 2$ region and $\mathrm{C} 2$ region are located at downstream side of the dam foundation; there are a total of 30 monitoring holes with 5 holes in each test region, including 1 single-hole sonic measuring hole, 1 group ( 3 holes) cross-sonic measuring hole, and 1 geological borehole measuring hole, as shown in Figure 4.

3.2. Unloading Relaxation Tests of Columnar Jointed Basalt. The test used the ultrasonic $\mathrm{P}$ wave detection method in a single borehole, and the detection probe had one emission component and two receiving components [32]. For every $0.1 \mathrm{~m}$ as the probe moved in the borehole along the axes, a 


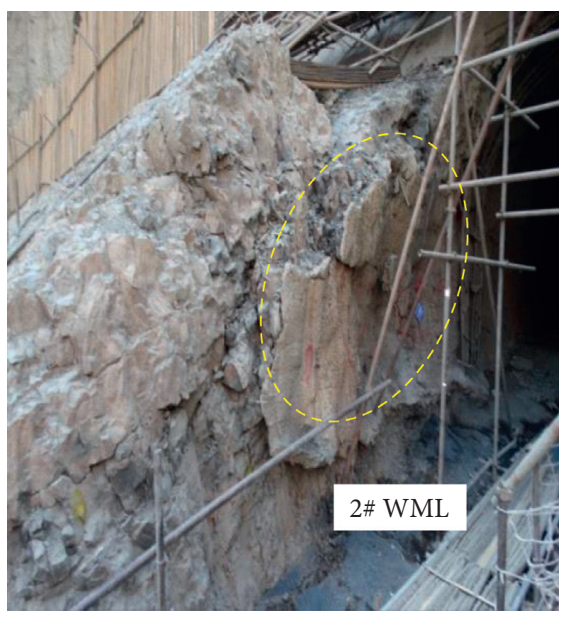

(a)

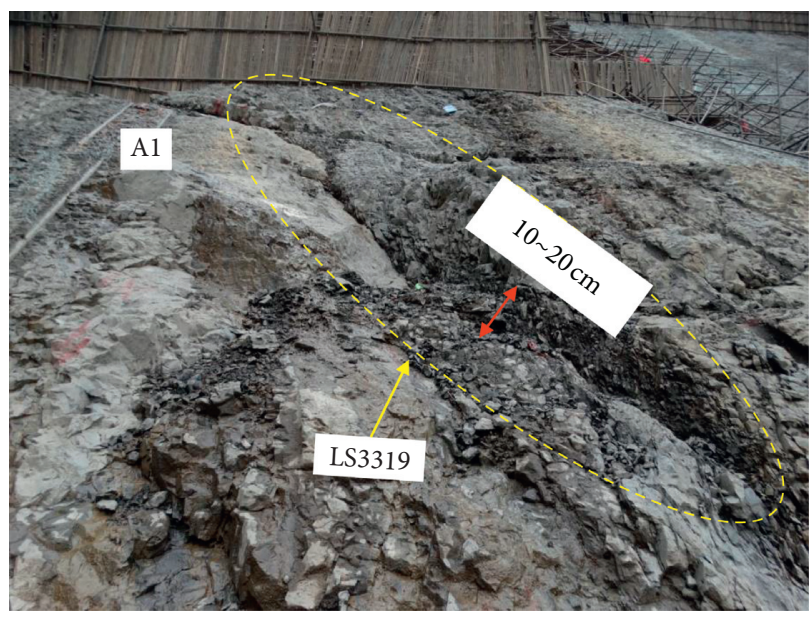

(b)

FIgURE 3: Typical failure of CJB on the left dam foundation. (a) Shearing dislocation at 2\# WML hole. (b) Relaxation of the intralayer dislocation zone LS3319.

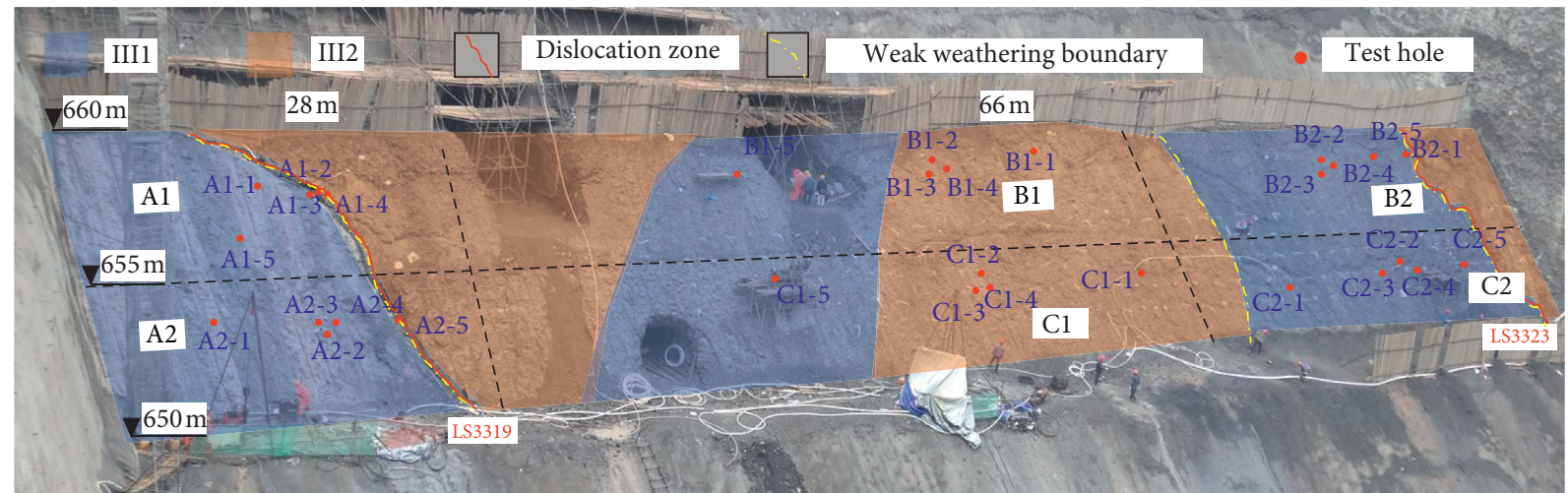

FIgUre 4: Layout of the CJB test zone on the left dam foundation.

wave-velocity curve along the borehole depth could be obtained.

By evaluating the tested curves, the relaxation depth of excavation damage zone of the CJB was defined by three ways in the following $[12,19]$ : (1) when there is no preblast wave velocity, the inflection point of the wave velocity curve is the relaxation depth; (2) when the inflection point of the wave velocity curve is not obvious, the CJB of III-1 is $4,700 \mathrm{~m} / \mathrm{s}$ and III-2 CJB is bounded by $4,000 \mathrm{~m} / \mathrm{s}$; (3) according to general engineering experience, when there is wave velocity before blasting, the boundary is where the wave velocity decreases by $10 \%$ after three consecutive points.

In order to fully understand the relaxation of the CJB test zone of the dam foundation, this study started on November 24,2014 , the day after the upper rock mass above the experimental zone was excavated by blast, shown in Table 1. In general, the wave velocity of relaxed rock mass is lower, while that of unrelaxed rock mass is higher. Due to the presence of local fracture zones in the depth of the borehole, the wave velocity of the rock mass is low, which is not calculated in the unrelaxed rock mass. In situ tests by the ultrasonic P wave apparatus showed as follows (Figure 5):

(1) On the upstream side of the dam foundation, the average $\mathrm{P}$ wave velocity of the unrelaxed CJB was approximately $5186 \mathrm{~m} / \mathrm{s}$, but that of the damaged columnar jointed rock mass was $3150 \mathrm{~m} / \mathrm{s}$ in average in subzone $\mathrm{A} 1$, and the average $\mathrm{P}$ wave velocity of the unrelaxed CJB was approximately $5249 \mathrm{~m} / \mathrm{s}$, but that of the damaged columnar jointed rock mass was $3284 \mathrm{~m} / \mathrm{s}$ in average in subzone A2.

(2) On the middle stream side of the dam foundation, the average $P$ wave velocity of the unrelaxed CJB was approximately $4962 \mathrm{~m} / \mathrm{s}$, but that of the damaged columnar jointed rock mass was $2844 \mathrm{~m} / \mathrm{s}$ in average in subzone $\mathrm{B} 1$, and the average $\mathrm{P}$ wave velocity of the unrelaxed CJB was approximately $4946 \mathrm{~m} / \mathrm{s}$, but that of the damaged columnar jointed rock mass was $2874 \mathrm{~m} / \mathrm{s}$ in average in subzone C1.

(3) On the downstream side of the dam foundation, the average $\mathrm{P}$ wave velocity of the unrelaxed CJB was 
TABLE 1: Unloading relaxation characteristics of columnar jointed basalt on left dam foundation.

\begin{tabular}{|c|c|c|c|c|c|}
\hline Description & $\begin{array}{l}\text { Average value of wave velocity in } \\
\text { relaxation zone }(\mathrm{m} / \mathrm{s})\end{array}$ & $\begin{array}{l}\text { Average value of wave velocity in } \\
\text { unrelaxed zone }(\mathrm{m} / \mathrm{s})\end{array}$ & $\begin{array}{l}\text { Average value of } \\
\text { relaxation depth }(\mathrm{m})\end{array}$ & Lithology & Location \\
\hline $\mathrm{A} 1$ & 3150 & 5186 & 0.8 & III-1 & Upstream \\
\hline A2 & 3284 & 5249 & 0.4 & III-1 & Upstream \\
\hline B1 & 2844 & 4962 & 2.9 & III-2 & $\begin{array}{l}\text { Middle } \\
\text { stream }\end{array}$ \\
\hline $\mathrm{C} 1$ & 2874 & 4946 & 3.0 & III-2 & $\begin{array}{l}\text { Middle } \\
\text { stream }\end{array}$ \\
\hline B2 & 2988 & 5070 & 2.7 & III-1 & Downstream \\
\hline $\mathrm{C} 2$ & 2980 & 5045 & 2.4 & III-1 & Downstream \\
\hline
\end{tabular}

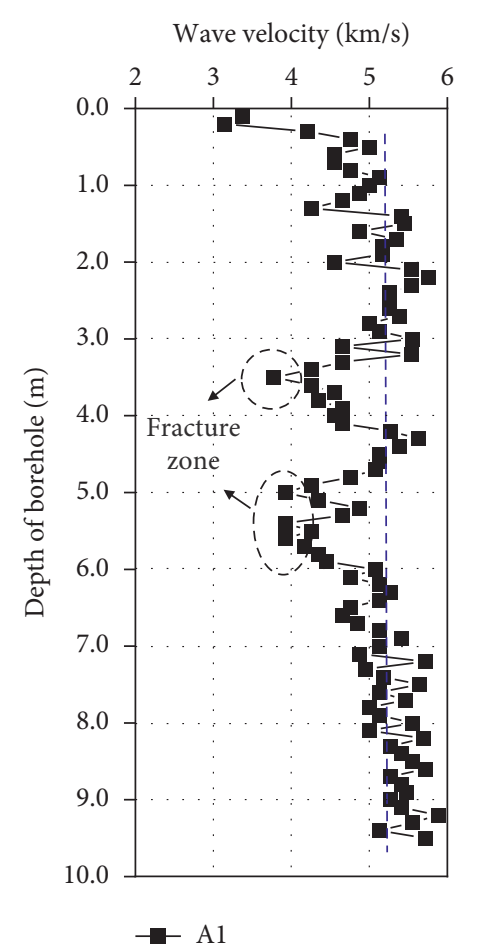

Wave velocity $(\mathrm{km} / \mathrm{s})$

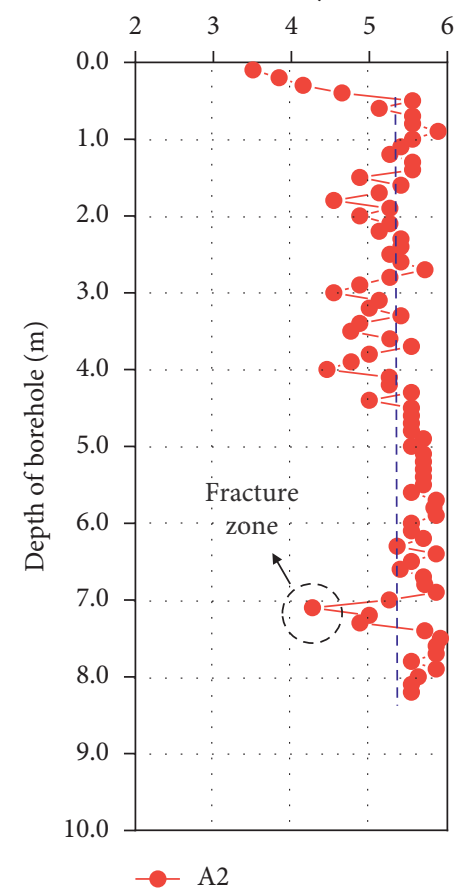

Wave velocity $(\mathrm{km} / \mathrm{s})$
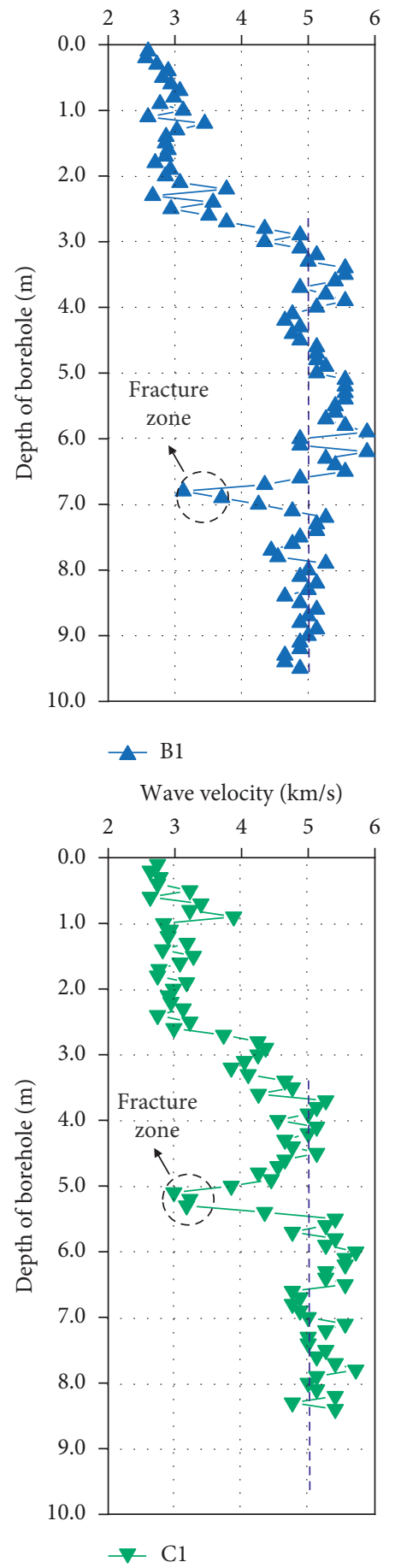

Wave velocity $(\mathrm{km} / \mathrm{s})$

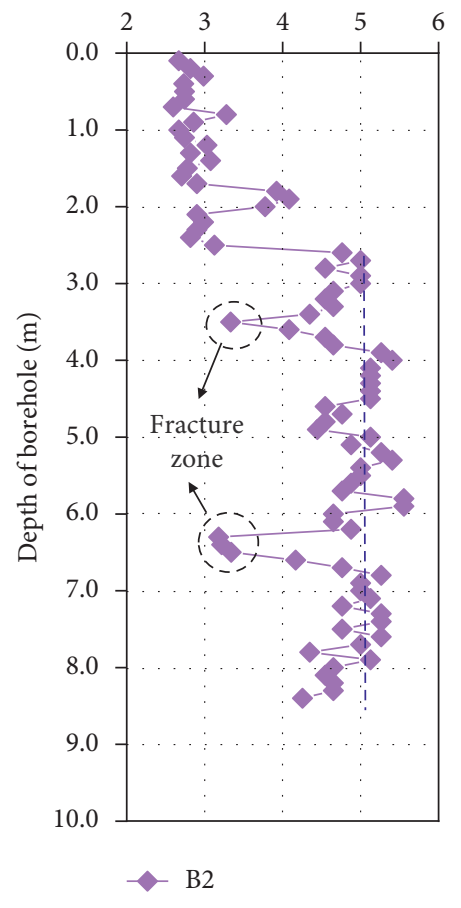

Wave velocity $(\mathrm{km} / \mathrm{s})$

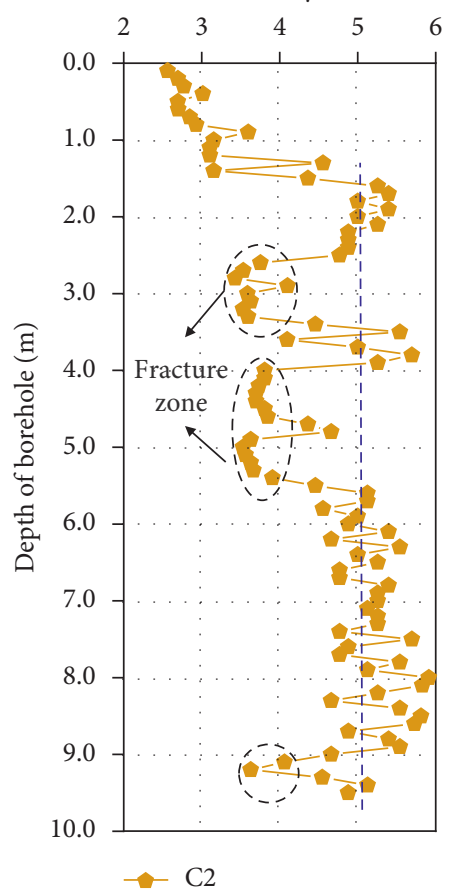

Figure 5: Typical tested $\mathrm{P}$ wave velocity vs. depth in the boreholes (1 month after excavation). 
approximately $5070 \mathrm{~m} / \mathrm{s}$, but that of the damaged columnar jointed rock mass was $2988 \mathrm{~m} / \mathrm{s}$ in average in subzone $\mathrm{B} 2$, and the average $\mathrm{P}$ wave velocity of the unrelaxed CJB was approximately $5045 \mathrm{~m} / \mathrm{s}$, but that of the damaged columnar jointed rock mass was $2980 \mathrm{~m} / \mathrm{s}$ in average in subzone C2.

\subsection{Unloading Relaxation Characteristics of Columnar Jointed} Basalt Test Zone. After nearly 8 months of continuous field tests, the results of the holes in the CJB test zone on the left dam foundation were obtained, including the relaxation depth (Figure 6) and its time-dependent evolution (Figure 7). The rock mass relaxation depth test of the columnar jointed basalt test zone from the elevation of $660 \sim 660 \mathrm{~m}$ on the left dam foundation showed as follows:

(1) The relaxation depth of A zone on the upstream side of the dam foundation was between 0.2 and $1.7 \mathrm{~m}$, with an average relaxation depth of $0.6 \mathrm{~m}$; the relaxation depth of B1 zone in the middle of the dam foundation was between 1.4 and $3.6 \mathrm{~m}$, with an average relaxation depth of $2.9 \mathrm{~m}$; the relaxation depth of zone $\mathrm{C} 1$ was between 2.4 and $3.5 \mathrm{~m}$, with an average relaxation depth of $3.0 \mathrm{~m}$. The relaxation depth of B2 zone on the downstream side of the dam foundation was between 1.0 and $4.1 \mathrm{~m}$, and with an average relaxation depth of $2.7 \mathrm{~m}$; the relaxation depth of C2 zone was between 1.2 and $4.3 \mathrm{~m}$, with an average relaxation depth of $2.4 \mathrm{~m}$. In general, the relaxation depth of the columnar joined basalt in the upstream of the dam foundation was minimum, the relaxation depth in the downstream of the dam foundation is middle, and the relaxation depth in the middle of the dam foundation is maximum, as shown in Table 1.

(2) The unloading relaxation in upstream side of dam foundation (test zone A) is mainly caused by the unloading of the blasting excavation in this section, and the time-dependent relaxation effect is not obvious. The relaxation depth caused by excavation blasting accounts for more than $70 \%$ of the total relaxation depth. The specific relaxation depth time history evolution is shown in Figure 7; the time effect of the unloading relaxation in middle stream and downstream of dam foundation (test zone B and C) is more obvious, generally lasts about 45 days, and the initial relaxation depth caused by blasting accounts for $20 \sim 50 \%$ of the total relaxation depth, as shown in Figure 7.

\section{Mechanical Response of Columnar Jointed Basalt during Excavation on the Left Dam Foundation}

4.1. Three-Dimensional Numerical Analysis. Based on the topographic data of the left dam foundation, a quasi-threedimensional numerical model reflecting the shape of the left dam foundation is established, and the mechanical response of rock mass during excavation in the CJB test zone on the left dam foundation is simulated emphatically. The $X$-direction width of the model is $800 \mathrm{~m}$, in which right boundary is the center of the valley, and the left boundary is beyond the top slope of the dam foundation. The Y-direction width of the model is $500 \mathrm{~m}$, including the upstream and downstream abutments. In the vertical direction, the elevation is from $900 \mathrm{~m}$ to $500 \mathrm{~m}$, as shown in Figure 8(a). In order to fully reflect the CJB excavation damage zone characteristics of dam foundation, the 3D numerical model considers the unfavorable geological structures such as fault F17 and F108, interlayer dislocation zones C3 and C31 , and intralayer dislocation zones LS331, LS3318, and LS3319 (Figure $8(\mathrm{~b})$ ). A $2 \mathrm{~m}$ protective layer is set on the foundation plane at $660 \mathrm{~m}$ in elevation. Meanwhile, the model includes WML2 hole and PSL2 hole, and fine mesh division is carried out for CJB at $600 \sim 660 \mathrm{~m}$ in elevation (Figure 8(c)).

For the special structural characteristics of the joint network and the transverse isotropic deformation and strength characteristics of the columnar joints, a mechanical model of CJB combining multiple sets of joint strength criteria was adopted [33], and the stiffness matrix of its transverse isotropic deformation was calculated by

$$
\begin{aligned}
{[K] } & =\left[\begin{array}{cccccc}
C_{11} & C_{12} & C_{13} & 0 & 0 & 0 \\
C_{12} & C_{22} & C_{13} & 0 & 0 & 0 \\
C_{13} & C_{13} & C_{33} & 0 & 0 & 0 \\
0 & 0 & 0 & C_{44} & 0 & 0 \\
0 & 0 & 0 & 0 & C_{66} & 0 \\
0 & 0 & 0 & 0 & 0 & C_{66}
\end{array}\right], \\
C_{11} & =C_{22}=\frac{\left(1+\mu_{12}\right)\left(1-\mu_{12}-2 n \mu_{13}^{2}\right)}{\left(1-n \mu_{13}^{2}\right)} \\
C_{12} & =\frac{E_{1}\left(\mu_{12}+n \mu_{13}^{2}\right)}{\left(1+\mu_{12}\right)\left(1-\mu_{12}-2 n \mu_{13}^{2}\right)}, \\
C_{13} & =\frac{E_{1} \mu_{13}}{1-\mu_{12}-2 n \mu_{13}^{2}}, \\
C_{33} & =\frac{E_{3}\left(1-\mu_{12}\right)}{1-\mu_{12}-2 n \mu_{13}^{2}}, \\
C_{44} & =\frac{E_{1}}{1+\mu_{12}}, \\
C_{3}, & \frac{E_{13}}{E_{3}},
\end{aligned}
$$

where $E_{1}$ and $\mu_{12}$ are the elastic modulus and Poisson's ratio perpendicular to the axial direction of the cylinder, respectively, and $E_{3}, \mu_{13}$, and $G_{13}$ are the elastic modulus, Poisson's ratio, and shear modulus parallel to the axial direction of the cylinder. 


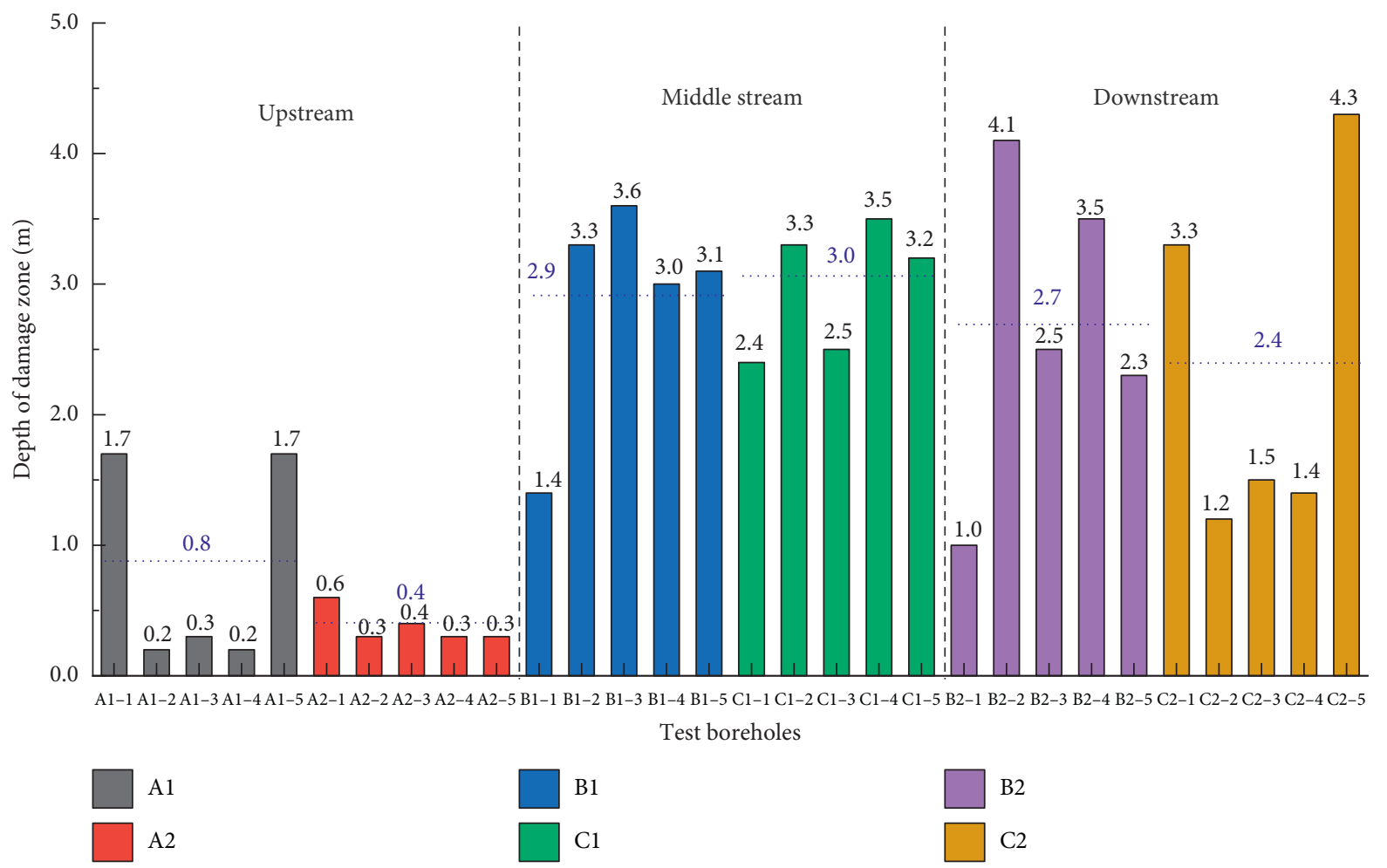

FIgURE 6: Total tested depths of EDZ in the CJB experimental zone (results at 8 months after excavation).

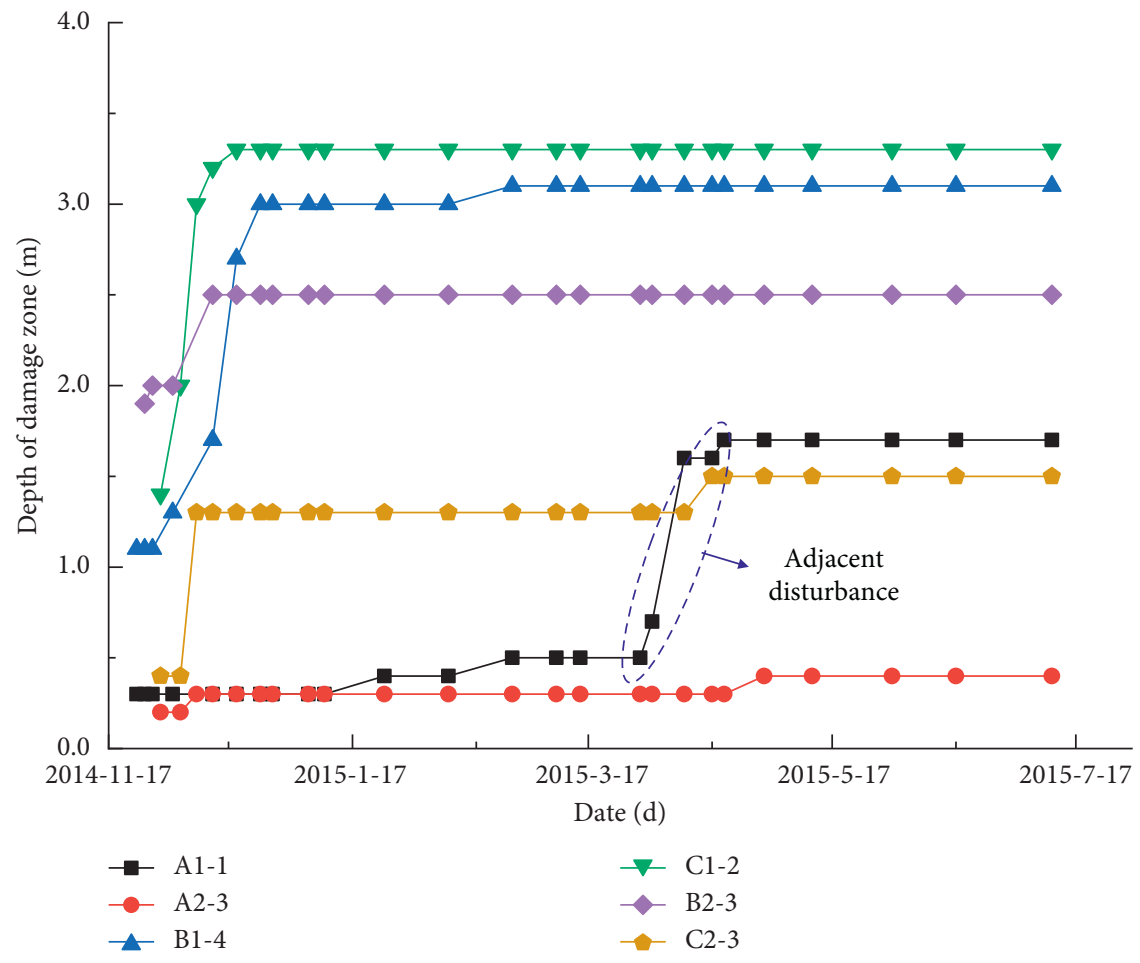

Figure 7: Typical temporal evolution of the CJB damage depth.

Unloaded fracture of CJB includes shear failure and tensile failure of the whole rock mass and each group of joints. Therefore, a combination of multiple strength criteria is adopted: (1) Mohr-Coulomb strength criterion with tensile cutoff is used to describe the fracture of intact rock block; (2) for the joint surfaces between columns with rough surfaces, the Barton-Bandis strength criterion with tensile cutoff is used to describe (equation (3)); (3) for hidden joint 


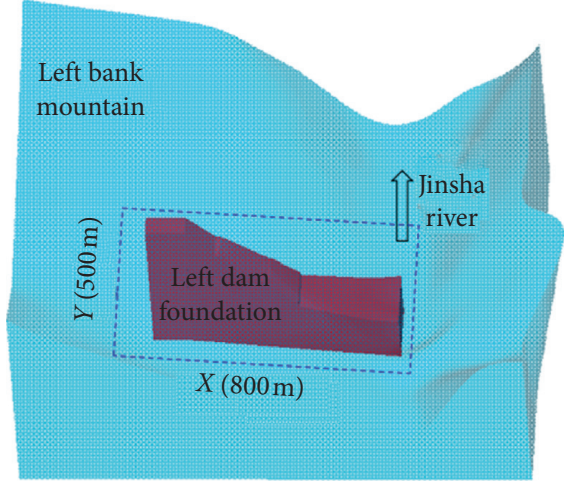

(a)

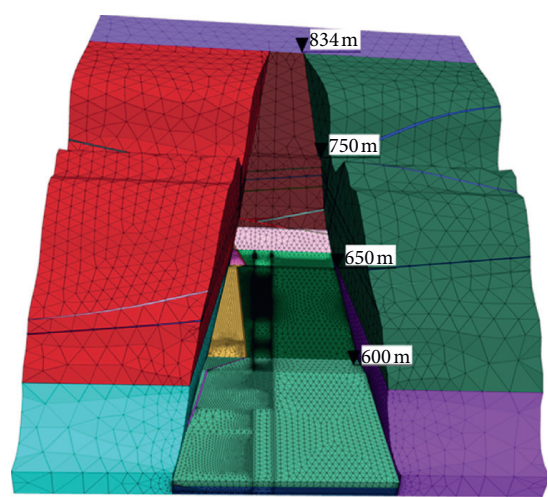

(b)

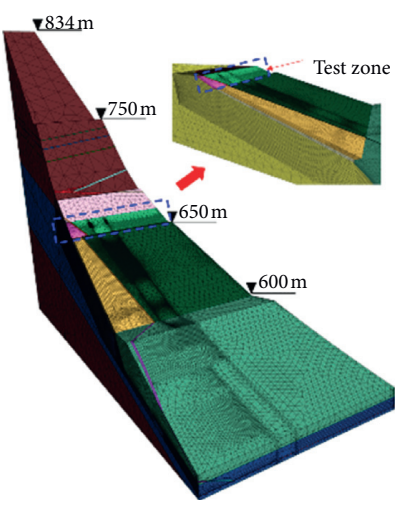

(c)

Figure 8: 3D calculation model of left dam foundation and fine mesh division of test zone. (a) Model location, (b) 3D mesh model, and (c) fine meshing.

surfaces with flat surface, Mohr-Coulomb strength criterion with tensile cutoff was adopted to describe (equations (4) $-(6))$

$$
\begin{aligned}
f_{i}^{s} & =\tau_{i}-\sigma_{3^{\prime} 3^{\prime}}^{i} \tan \varphi_{m}^{i}, \\
\varphi_{m}^{i} & =\operatorname{JRC}^{i} \lg \left(\frac{\mathrm{JCS}^{i}}{\left|\sigma_{3^{\prime} 3^{\prime}}^{j i}\right|}\right)+\varphi_{r}^{i},
\end{aligned}
$$

where $f_{i}^{s}, \varphi_{m}^{i}, \varphi_{r}^{i}, \mathrm{JRC}^{i}$, and $\mathrm{JCS}^{i}$ are, respectively, the shear strength, friction Angle, residual friction angle, joint roughness coefficient, and joint wall strength of joint plane:

$$
\begin{aligned}
& f_{j 3}^{s}=\tau_{j 3}-\sigma_{3^{\prime} 3^{\prime}} \tan \varphi_{j 3}-C_{j 3}, \\
& f_{j 3}^{t}=\sigma_{3^{\prime} 3^{\prime}}-\sigma_{j 3}^{t}, \\
& h_{j 3}=\tau_{j 3}+\sigma_{j 3}^{t} \tan \varphi_{j 3}-C_{j 3}+\left(\sqrt{1+\tan ^{2} \varphi_{j 3}}-\tan \varphi_{j 3}\right),
\end{aligned}
$$

where $f_{j 3}^{s}, f_{j 3}^{t}$, and $h_{j 3}$ are shear yield criterion, tensile yield criterion, and shear-tensile boundary mixed yield criterion for the near-horizontal hidden joint plane in the column, respectively. $\tau_{j 3}$ and $\sigma_{3^{\prime} 3^{\prime}}$ are the shear stress and normal stress acting on the near-horizontal hidden joint plane in the column, respectively. $C_{j 3}, \varphi_{j 3}$, and $\sigma_{j 3}^{t}$ are the cohesion, internal friction angle, and tensile strength near the horizontal hidden joint surface in the column. The mechanical parameters used in the equation are determined based on diversion tunnel inversion, respectively [33].

\subsection{Mechanical Response Analysis of Columnar Jointed Basalt} Test Zone during Excavation. The distribution of minimum principal stress of rock mass after excavation and unloading can reflect the potential risk of unloading relaxation after excavation. Meanwhile, RFD is used as an evaluation index of rock mass fracture, and its magnitude is used to quantitatively characterize the degree of rock mass fracture. Usually, the zone with $\mathrm{RFD} \geq 1.0$ is defined as the range of rock mass fracture depth, and $\mathrm{RFD}=2.0$ means that the rock mass is completely fractured. Thus, the numerical calculation of the relaxation fracture zone can be unified with the measured relaxation depth and the visible fracture depth of rock mass [34]. Therefore, this paper will analyze the mechanical response of the columnar joined basalt test zone of the dam foundation under the current excavation state from the two aspects, including the minimum principal stress distribution and the fracture index RFD. The details are as follows:

(1) With the excavation of the left dam foundation, the stress state of the dam foundation changes, and the tensile stress occurs locally in the CJB test zone (the elevation is $660 \sim 650 \mathrm{~m}$ ), which indicates that the unloading effect is significant after the excavation.

(2) After the excavation of the left dam foundation, the surface of the dam foundation is damaged by unloading relaxation, especially in the CJB section, and the damage is obvious. The results of numerical analysis show that the relaxation depth of the columnar joined basalt test zone is small in the upstream, generally about $1 \mathrm{~m}$ (Figure 9), the largest in the middle, averaging $3 \sim 4 \mathrm{~m}$, up to $5 \mathrm{~m}$ locally (Figure 10), and the relaxation depth of the downstream of the dam foundation is $2 \sim 3 \mathrm{~m}$ on average (Figure 11). The RFD value on the surface of the dam foundation is greater than 1.5 , which means that unloading relaxation of the CJB in this region seriously.

(3) The numerical results show that the unloading relaxation zone of the dam foundation rock mass is consistent with the unloading tensile stress, which indicates that the unloading relaxation of the CJB is mainly caused by the tensile failure of the joints of the CJB under tensile stress.

\section{Analysis of the Difference of Unloading Relaxation Depths of Columnar Jointed Basalt}

5.1. Influence of Rock Mass Quality on Unloading Relaxation of Columnar Jointed Basalt. The field geological data show 


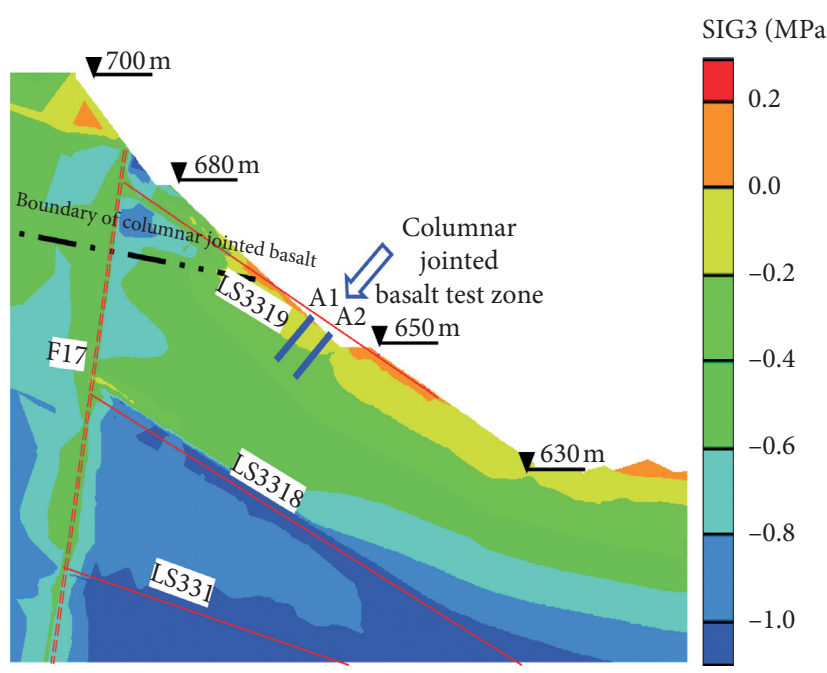

(a)

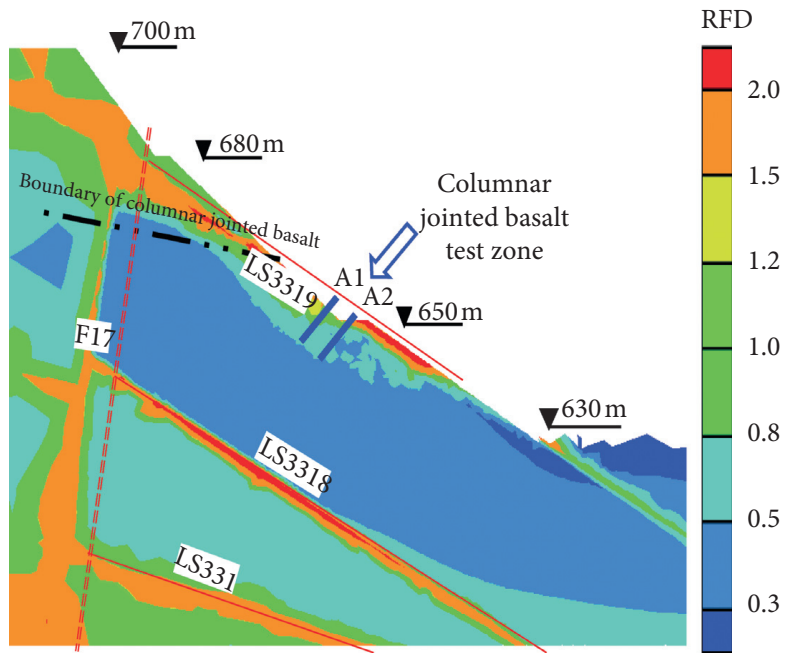

(b)

FIgURE 9: Unloading relaxation characteristics of CJB on the upstream side of the left dam foundation (A1 and A2 zones). (a) Minimum principal stress; (b) rock failure zone RFD.

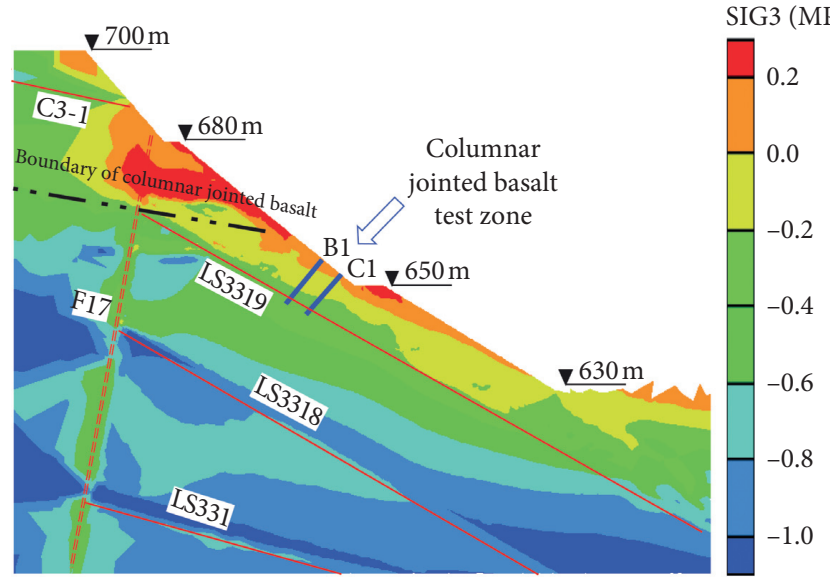

(a)

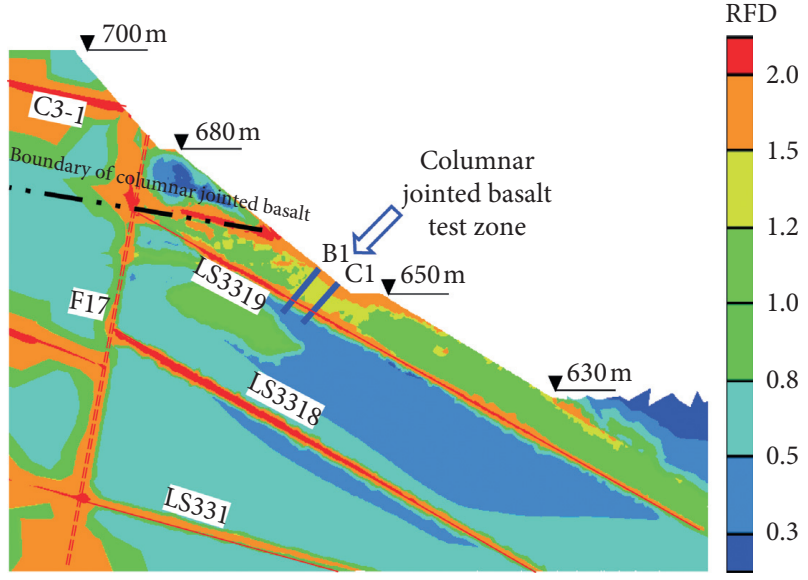

(b)

Figure 10: Unloading relaxation characteristics of CJB in the middle stream of the left dam foundation (B1 and C1 zones). (a) Minimum principal stress; (b) rock failure zone RFD.

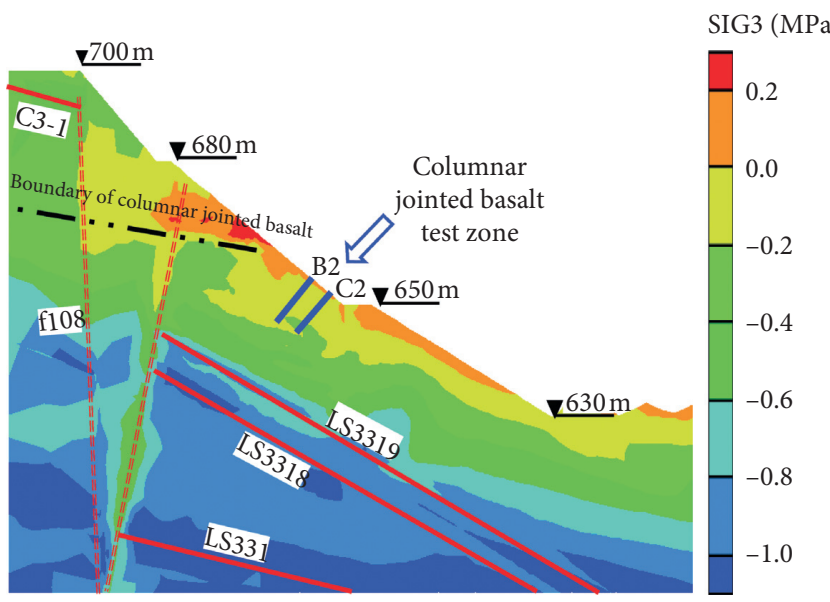

(a)

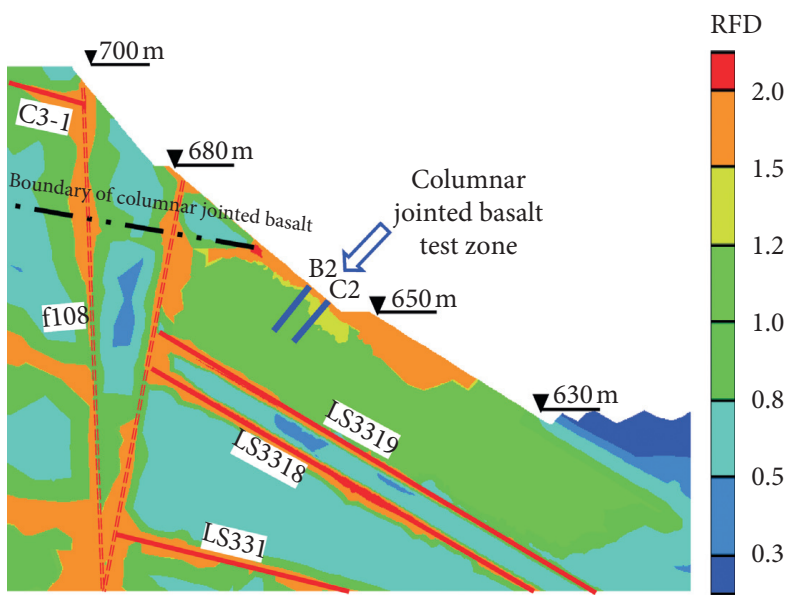

(b)

FIgURE 11: Unloading relaxation characteristics of CJB at the downstream of the left dam foundation (B2 and C2 zones). (a) Minimum principal stress; (b) rock failure zone RFD. 


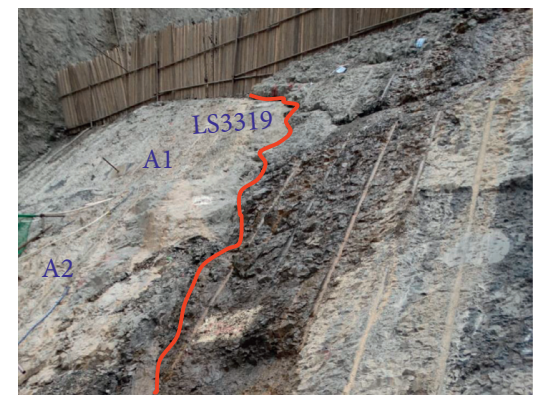

(a)

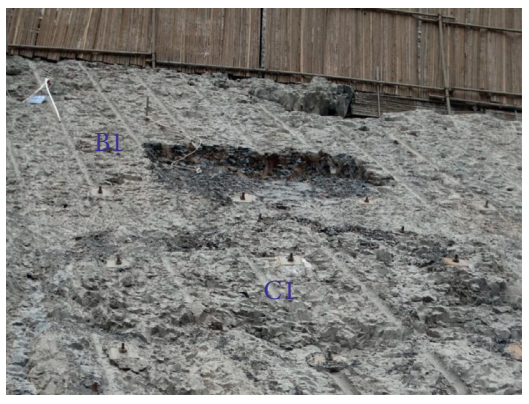

(b)

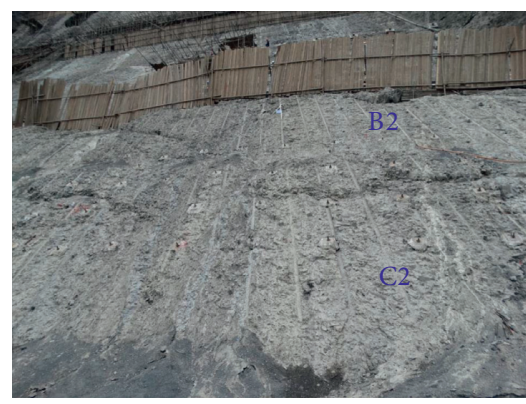

(c)

FIGURE 12: Outcropping rock mass on the surface of CJB test zone. (a) Fresh and intact rock mass, (b) weathered obviously rock mass, and (c) jointly developed rock mass.

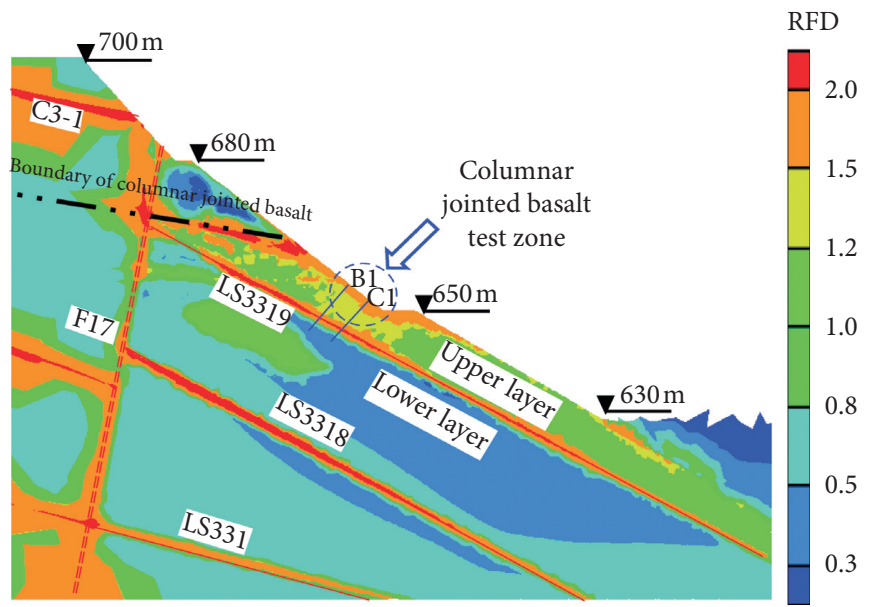

(a)

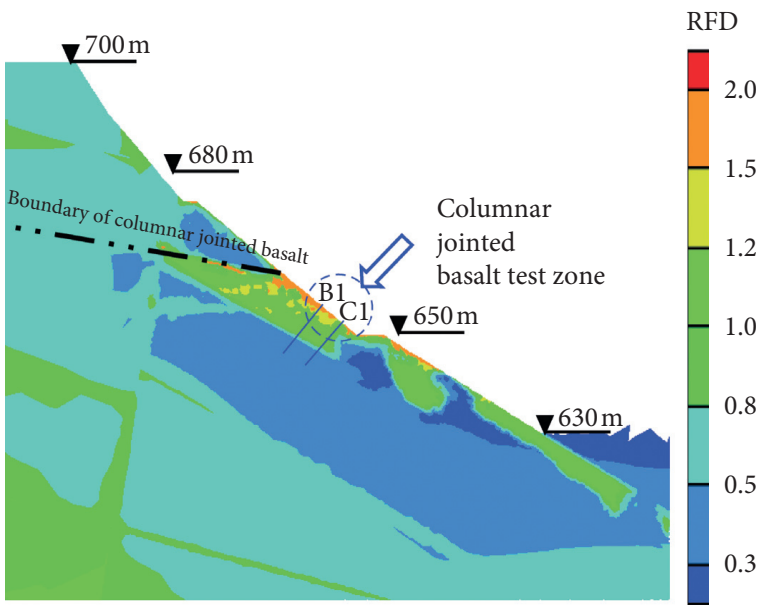

(b)

Figure 13: Influence of disadvantageous geological structure on unloading relaxation in the columnar joined basalt test zone on left dam foundation. (a) With geological structure; (b) without geological structure.

that the CJB in A zone at the upstream side of the dam foundation is mostly III-1 rock mass, and the rock mass is usually compact, fresh, and complete, without weathering or weathering is not obvious. Most of the CJB in B1 and $\mathrm{C} 1$ zones at the middle stream of the dam foundation are III-2 rock mass. Compared with A zone, hidden joints are more developed and the tock mass is obviously weathered. In addition, although the CJB in B2 and C2 zones at the downstream side of the dam foundation is mostly III-1 rock mass, low-dip fractures and intrabedded dislocation zones are relatively developed, as shown in Figure 12.

The acoustic test results of CJB showed that the average wave velocity in relaxation zone was about $3200 \mathrm{~m} / \mathrm{s}$, and that in unrelaxed zone was about $5200 \mathrm{~m} / \mathrm{s}$. The average wave velocity in zone $\mathrm{B}$ and $\mathrm{C}$ was about $2,900 \mathrm{~m} / \mathrm{s}$ in the relaxed zone and $5,00 \mathrm{~m} / \mathrm{s}$ in the unrelaxed zone. In general, field observation and acoustic test results show that the quality of CJB at on upstream side of dam foundation was better than that in zones B and C, which was consistent with the fact that the relaxation depth in zone A was smaller than that in zones B and C.
5.2. Influence of Disadvantageous Geological Structures on Unloading Relaxation of Columnar Jointed Basalt. In order to study the effect of disadvantageous geological structure on the unloading relaxation of columnar joined basalt, the numerical analysis of excavation unloading of dam foundation with and without disadvantageous geological structure is carried out in this paper. The results show as follows (Figure 13): (1) when the left dam foundation contains disadvantageous geological structures such as fault F7 and LS3319, the relaxation depth of the columnar joined basalt test zone can reach $4 \sim 5 \mathrm{~m}$, and the relaxation degree of the surface rock mass is greater; (2) when there is no unfavorable geological structure, the relaxation depth and relaxation degree decrease accordingly.

Serious relaxation failure occurred in the nearby rock mass due to the existence of disadvantageous geological structure, and the unload relaxation damage of CJB in the upper layer will be further aggravated. Field observation show that test zone $\mathrm{A}$ is located below dislocation zone LS3319, and test zones B and C are located above dislocation zone LS3319, and seriously slip dislocation was observed 


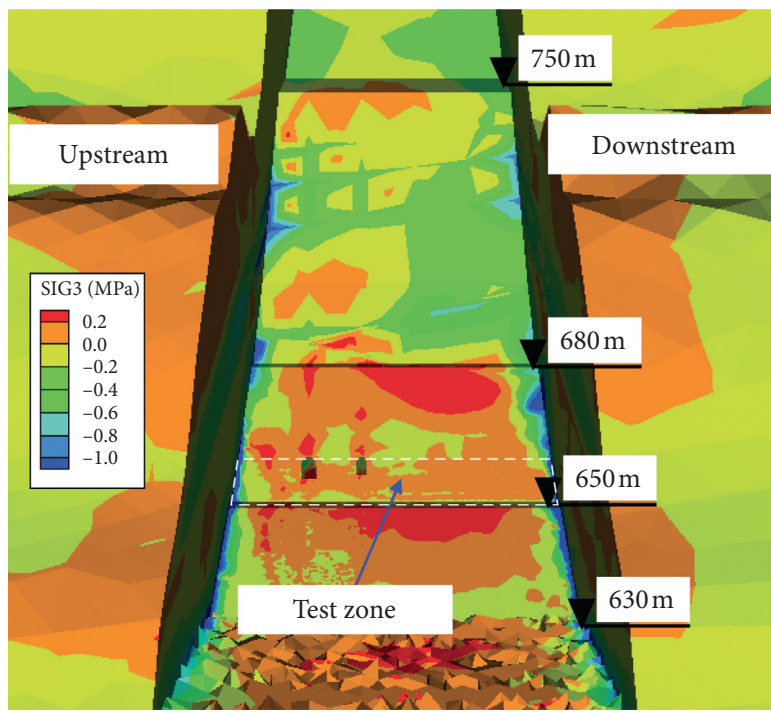

(a)

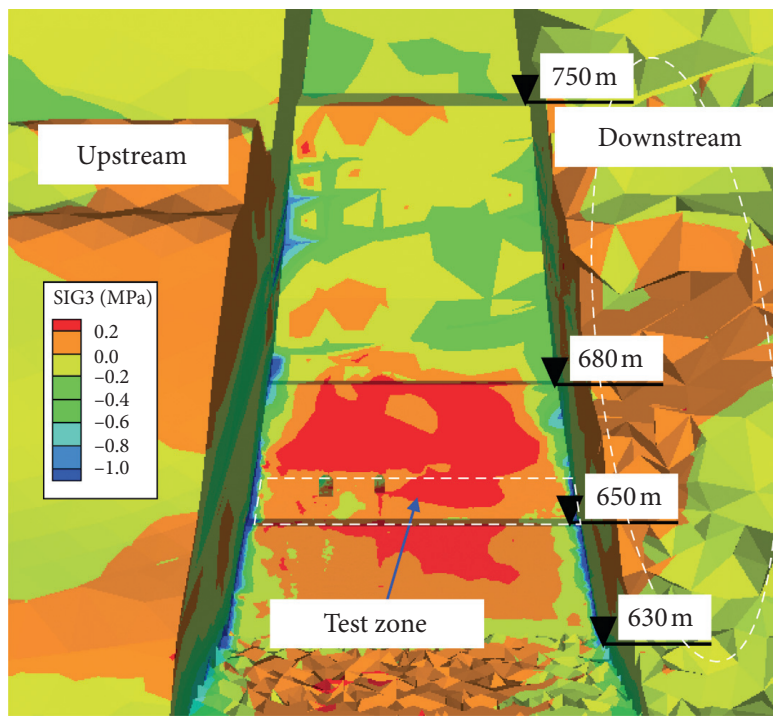

(b)

FIGURE 14: Influence of excavation of downstream abutment on minimum principal stress distribution on left dam foundation. (a) Unexcavated downstream abutment; (b) excavated downstream abutment.

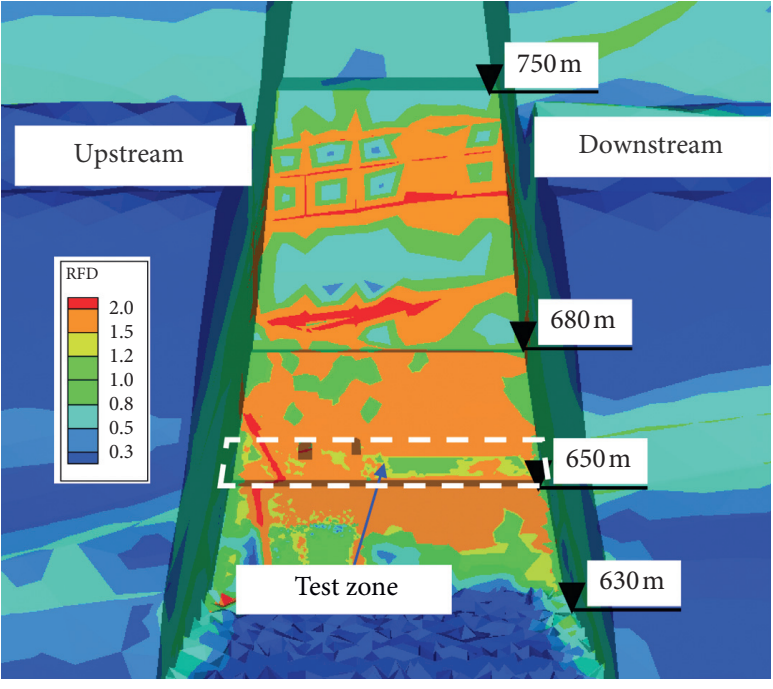

(a)

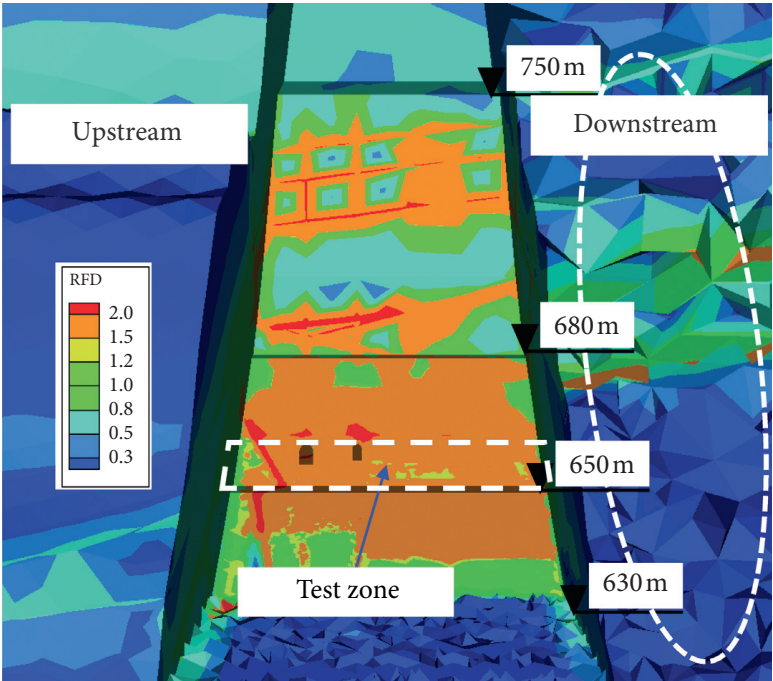

(b)

FIGURE 15: Influence of excavation of downstream abutment on minimum principal stress distribution on left dam foundation. (a) Unexcavated downstream lateral abutment; (b) excavated downstream lateral abutment.

around LS3319. The unloading relaxation damage of CJB in test zones $\mathrm{B}$ and $\mathrm{C}$ will be seriously affected by the dislocation zone LS3319, as shown in Figures 9-11.

5.3. Influence of Surrounding Constraints on Unloading Relaxation Damage of Columnar Jointed Basalt. The conditions after excavation showed that the upstream abutment of the left dam foundation of the Baihetan Hydropower Station was steep, and rarely excavated, which has a strong constraint on the dam foundation. However, the downstream is weak and with a lot of excavation, causing the relatively weak constraint on the dam foundation. The test zones A1 and A2 were located in the upstream of the dam foundation, where the constraint was strong. The test zones B2 and C2 were located in the downstream of the dam foundation, where the constraint was weak. The test zones $\mathrm{B} 1$ and $\mathrm{C} 1$ were located in the middle stream of the dam foundation, far away from the upstream and downstream dam abutments, where the constraint effect was the weakest.

To study the influence of dam abutment on the unloading relaxation of columnar joined basalt, the numerical analysis before and after excavation of the downstream abutment in the left dam foundation was carried out. 
The calculation results indicated that (1) with the excavation of downstream abutment, the range of stress release zone and damage zone was further enlarged and (2) with the excavation of the downstream abutment, the range of stress release zone and damage zone in the columnar joined basalt on the dam foundation was shifted from upstream to downstream (Figures 14 and 15).

\section{Conclusions}

In this paper, the relaxation characteristics of columnar joined basalt on the left dam foundation of the Baihetan Hydropower Station were studied by the single-hole acoustic in situ testing technique, and the relaxation mechanism was also analyzed by a three-dimensional numerical analysis method. Moreover, the difference of relaxation depth in different parts of the test zone was discussed, and the main conclusions were as follows:

(1) The joint network inside the CJB included intercolumnar joints and internal hidden joints, which is prone to unloading relaxation failure. The difference in the quality of the rock mass results in different unloading relaxation depth of columnar jointed basalt, which have a time-dependent evolution. Specifically, the worse quality of the rock mass, the greater in the depth of unloading relaxation and the time effect is more significant.

(2) Numerical results indicated that the unloading performance of CJB on dam foundation is mainly caused by the joint opening under tension stress during excavation, in which joint opening results in poor mechanical properties of rock mass.

(3) The disadvantageous structure intensified the unloading relaxation effect of the nearby CJB (especially the upper rock mass) to a certain extent; thus, much attention about the intersection of columnar jointed rock mass and disadvantageous geological structure should be carried.

(4) The restraints of upstream and downstream abutments can reduce the unloading relaxation effect of CJB. Two support measures, such as the prestressed anchor cable support and timely concrete backfill, have been suggested.

\section{Data Availability}

The data used to support the findings of the study are available from the corresponding author upon request.

\section{Conflicts of Interest}

The authors declare that there are no conflicts of interest regarding the publication of this paper.

\section{References}

[1] W. S. Dershowitz and H. H. Einstein, "Characterizing rock joint geometry with joint system models," Rock Mechanics and Rock Engineering, vol. 21, no. 1, pp. 21-51, 1988.
[2] M. Cai and H. Horii, "A constitutive model of highly jointed rock masses," Mechanics of Materials, vol. 13, no. 3, pp. 217-246, 1992.

[3] J. Hudson, J. Harrison, and M. Popescu, "Engineering rock mechanics: an introduction to the principles," Applied Mechanics Reviews, vol. 55, no. 2, p. 72, 2002.

[4] M. Sharifzadeh, M. Sharifi, and S. M. Delbari, "Back analysis of an excavated slope failure in highly fractured rock mass: the case study of Kargar slope failure (Iran)," Environmental Earth Sciences, vol. 60, no. 1, pp. 183-192, 2010.

[5] Q. Jiang, X.-T. Feng, T.-B. Xiang, and G.-S. Su, "Rockburst characteristics and numerical simulation based on a new energy index: a case study of a tunnel at 2,500 m depth," Bulletin of Engineering Geology and the Environment, vol. 69, no. 3, pp. 381-388, 2010.

[6] G.-F. Liu, Q. Jiang, G.-L. Feng et al., "Microseismicity-based method for the dynamic estimation of the potential rockburst scale during tunnel excavation," Bulletin of Engineering $\mathrm{Ge}$ ology and the Environment, vol. 80, no. 5, pp. 3605-3628, 2021.

[7] S. I. Tomkeieff, "The basalt lavas of the giant's causeway district of Northern Ireland," Bulletin of Volcanology, vol. 6, no. 1, pp. 89-143, 1940.

[8] L. Goehring and S. W. Morris, "Scaling of columnar joints in basalt," Journal of Geophysical Research: Solid Earth, vol. 113, no. B10, 2008.

[9] B. C. Noble, "Quantitative study of columnar jointing," Geological Society of America Bulletin, vol. 70, no. 3, 1959.

[10] X.-J. Hao, X.-T. Feng, C.-X. Yang, Q. Jiang, and S.-J. Li, "Analysis of EDZ development of columnar jointed rock mass in the baihetan diversion tunnel," Rock Mechanics and Rock Engineering, vol. 49, no. 4, pp. 1289-1312, 2016.

[11] X. J. Hao, X. T. Feng, S. J. Li et al., "Failure mode of columnar jointed basalt tunnel and its mechanism simulation," Rock and Soil Mechanics, vol. 36, no. 3, pp. 837-846, 2015.

[12] S. C. Maxwell, R. P. Young, and R. S. Read, "A micro-velocity tool to assess the excavation damaged zone," International Journal of Rock Mechanics \& Mining Sciences, vol. 35, no. 2, pp. 235-247, 1998.

[13] A. Millard, J. Massmann, A. Rejeb, and S. Uehara, "Study of the initiation and propagation of excavation damaged zones around openings in argillaceous rock," Environmental Geology, vol. 57, no. 6, pp. 1325-1335, 2009.

[14] S. J. Li, X. T. Feng, Z. H. Li et al., "In situ experiments on width and evolution characteristics of excavation damaged zone in deeply buried tunnels," Science China, vol. 54, no. 1, pp. 167-174, 2011.

[15] Q. Fan, X. Feng, W. Weng, Y. Fan, and Q. Jiang, "Unloading performances and stabilizing practices for columnar jointed basalt: a case study of Baihetan hydropower station," Journal of Rock Mechanics and Geotechnical Engineering, vol. 9, no. 6, pp. 1041-1053, 2017.

[16] Q. Fan, Z. Wang, J. Xu, M. Zhou, Q. Jiang, and G. Li, "Study on deformation and control measures of columnar jointed basalt for Baihetan super-high arch dam foundation," Rock Mechanics and Rock Engineering, vol. 51, no. 8, pp. 2569-2595, 2018.

[17] Q. Jiang, B. Wang, X.-T. Feng et al., "In situ failure investigation and time-dependent damage test for columnar jointed basalt at the Baihetan left dam foundation," Bulletin of Engineering Geology and the Environment, vol. 78, no. 6, pp. 3875-3890, 2019.

[18] Q. Jiang, X.-T. Feng, Y. H. Hatzor, X.-J. Hao, and S.-J. Li, "Mechanical anisotropy of columnar jointed basalts: an example from the Baihetan hydropower station, China," Engineering Geology, vol. 175, pp. 35-45, 2014. 
[19] S. F. Pei, X. T. Feng, J. C. Zhang et al., "Time-dependent relaxation characteristics of columnar jointed basalts in highslope dam foundation during excavation," Rock and Soil Mechanics, vol. 39, no. 10, pp. 3743-3754, 2018.

[20] Y. Ning, W. Y. Xu, W. T. Zheng et al., "Study of random simulation of columnar jointed rock mass and its representative elementary volume scale," Yanshilixue Yu Gongcheng Xuebao/Chinese Journal of Rock Mechanics and Engineering, vol. 27, no. 6, pp. 1202-1208, 2008.

[21] W. T. Zheng, W. Y. Xu, Y. Ning et al., "Scale effect and anisotropy of deformation modulus of closely jointed basaltic mass," Journal of Engineering Geology, vol. 18, no. 4, pp. 559-565, 2010.

[22] S.-J. Di, W.-Y. Xu, Y. Ning, W. Wang, and G.-Y. Wu, "Macromechanical properties of columnar jointed basaltic rock masses," Journal of Central South University of Technology, vol. 18, no. 6, pp. 2143-2149, 2011.

[23] D. Yan, W. Xu, W. Wang et al., "Research of size effect on equivalent elastic modulus of columnar jointed rock mass," Chinese Journal of Geotechnical Engineering, vol. 34, no. 2, pp. 243-250, 2012.

[24] A. C. Shi, M. F. Tang, and Q. J. Zhou, "Research of deformation characteristics of columnar jointed basalt at Baihetan hydropower station on Jinsha river," Chinese Journal of Rock Mechanics and Engineering, vol. 27, no. 10, pp. 2079-2086, 2008.

[25] X.-T. Feng, X.-J. Hao, Q. Jiang, S.-J. Li, and J. A. Hudson, "Rock cracking indices for improved tunnel support design: a case study for columnar jointed rock masses," Rock Mechanics and Rock Engineering, vol. 49, no. 6, pp. 2115-2130, 2016.

[26] Y. H. Hatzor, X. T. Feng, S. J. Li et al., "Tunnel reinforcement in columnar jointed basalts: the role of rock mass anisotropy," Tunnelling and Underground Space Technology, vol. 46, no. 1-11, 2015.

[27] X. Hao, W. Du, Y. Zhao et al., "Dynamic tensile behaviour and crack propagation of coal under coupled static-dynamic loading," International Journal of Mining Science and Technology, vol. 30, no. 5, pp. 659-668, 2020.

[28] X. Hao, Y. Wei, K. Yang et al., "Anisotropy of crack initiation strength and damage strength of coal reservoirs," Petroleum Exploration and Development, vol. 48, no. 1, pp. 243-255, 2021.

[29] G.-L. Feng, B.-R. Chen, Q. Jiang, Y.-X. Xiao, W.-J. Niu, and P.-X. Li, "Excavation-induced microseismicity and rockburst occurrence: similarities and differences between deep parallel tunnels with alternating soft-hard strata," Journal of Central South University, vol. 28, no. 2, pp. 582-594, 2021.

[30] J. R. Xu, A. C. Shi, C. Y. Chou et al., Engineering Geology Report for Left-Bank and Riverbed Dam Foundation Excavation Treatment during Detail Design Phase of Construction of Baihetan Hydropower Station in Jinsha River, China Hydropower Electric Consultant Corporation, East China Investigation and Design Institute, Hangzhou, China, 2015, in Chinese.

[31] J. R. Xu, A. C. Shi, C. Y. Chou et al., Engineering Geology Report for Excavation Treatment of Columnar Jointed Basalt Dam Foundation during Detail Design Phase of Construction of Baihetan Hydropower Station in Jinsha River, China Hydropower Electric Consultant Corporation, East China Investigation and Design Institute, Hangzhou, China, 2015, in Chinese.

[32] A. Aydin, "Upgraded ISRM suggested method for determining sound velocity by ultrasonic pulse transmission technique," Rock Mechanics\&Rock Engineering, vol. 47, no. 1, pp. 255-259, 2014.

[33] X. J. Hao, Time-Dependent Excavation Damaged Zone Development of Columnar Jointed Rock Mass and Cracking Restraint Method for Hard Rock Tunnels, Institute of Rock and Soil Mechanics, Chinese Academy of Sciences, Wuhan, China, 2015.

[34] Q. Jiang, X. T. Feng, S. J. Li et al., "Cracking-restraint design method for large underground caverns with hard rock under high geostress condition and its practical application," Chinese Journal of Rock Mechanics and Engineering, vol. 38, no. 6, pp. 1081-1101, 2019. 